\title{
' 100 metres to the liquor store and 300 meters to the cemetery' - individual, social, environmental and organisational facilitators and barriers to thriving in Swedish sheltered housing models
}

\author{
Laura Corneliusson $^{1 \star ~(D), ~ A n d e r s ~ S k o ̈ l d u n g e r ~}{ }^{1,2}$, Karin Sjögren ${ }^{1}$ and David Edvardsson ${ }^{1,3,4}$ \\ ${ }^{1}$ Department of Nursing, Umeå University, Umeå, Sweden, ${ }^{2}$ Department of Neurobiology, Care Sciences \\ and Society, Division of Neurogeriatrics, Karolinska Institutet, Stockholm, Sweden, ${ }^{3}$ School of Nursing and \\ Midwifery, La Trobe University, Melbourne, Australia and ${ }^{4}$ Austin Health, Melbourne, Australia \\ ${ }^{*}$ Corresponding author. Email: laura.corneliusson@umu.se
}

(Accepted 7 June 2021; first published online 18 August 2021)

\begin{abstract}
In Sweden, sheltered housing is a housing model that provides accessible apartments with elevated social possibilities for older people. The environment within sheltered housing is expected to support resident health and reduce the need for care services. A previous study has shown that with increasing levels of depressive mood and decreasing levels of self-rated health and functional status, those residing in sheltered housing report higher levels of thriving compared to those ageing in place. Therefore, the aim of this study was to illuminate aspects of sheltered housing that are facilitators and/or barriers to thriving. Seven semi-structured group interviews in five different sheltered housing accommodations in Sweden were conducted between April 2019 and January $2020(\mathrm{~N}=38)$. The results, analysed using qualitative content analysis and presented in a model developed by Grol and Wensing, illuminate the four main categories of facilitators and barriers to thriving: individual factors, social context, environmental factors and organisational context. The results of this study show that the factors that influence experiences of thriving in sheltered housing are multifaceted and interconnected. Although the supportive environment provided in sheltered housing seems to contribute to thriving, the limited consideration towards the shifting health of residents is a barrier to thriving. The results of this study may assist in implementing tailored interventions to help support thriving on various levels.
\end{abstract}

Keywords: sheltered housing; thriving; wellbeing; housing for the elderly; aged; social participation

\section{Introduction}

Thriving is a concept which denotes the individual's wellbeing in the context of their place of residence, by capturing experiences of the interaction between the person, the human environment and the non-human environment (Bergland 
Table 1. Conceptual comparisons: quality of life, wellbeing and thriving

\begin{tabular}{ll}
\hline Concept & \multicolumn{1}{c}{ Description } \\
\hline Quality of life & $\begin{array}{l}\text { Life satisfaction, including features such as values, beliefs and abilities (Pinto } \\
\text { et al., 2017) }\end{array}$ \\
Wellbeing & Psycho-spiritual perception of happiness or satisfaction (Pinto et al., 2017) \\
Thriving & Lived experiences of situated contentment (Baxter et al., 2021) \\
\hline
\end{tabular}

et al., 2015). Thriving, which in this context is understood as situated contentment, is often described as a process which involves seeking a balance between expectations and reality, as well as the ambition of optimal interactions in the human- and non-human environment (Bergland and Kirkevold, 2006; Patomella et al., 2016). In contrast to wellbeing and quality of life, for which definitions vary vastly but which are often understood as evaluations of life satisfaction (Pinto et al., 2017; Edvardsson et al., 2019), thriving has been defined as a holistic concept denoting lived experiences of situated contentment (Baxter et al., 2021). While wellbeing is often used to denote a subjective psycho-spiritual perception of happiness or satisfaction, and quality of life as a broader concept of life satisfaction encompassing features such as, but not limited to, values, beliefs and abilities (Pinto et al., 2017), thriving is unique in exploring the interplay of features within a specific context that effect wellbeing, providing a perspective specific to a certain situation (Bergland and Kirkevold, 2006; Patomella et al., 2016; Baxter et al., 2021) (Table 1).

Thriving has been operationalised in an instrument called the TOPAS which explores how people experience thriving in their current setting (Bergland et al., 2015), providing a valuable measure for exploring experiences of situated contentment in housing models specifically designated for older people. Thriving has previously been qualitatively explored primarily in nursing home settings, and the thriving model developed by Bergland and Kirkevold (2006), based on interviews of nursing home residents in Norway, identified six dimensions relevant to thriving in nursing home settings. These dimensions are: mental attitude, quality of care and care-givers, positive relationships with other residents, participation in meaningful activities, opportunities to go outside, relationships with family and aspects in the physical environment (Bergland and Kirkevold, 2006). In this model, the mental attitude is the innermost core to thriving, with other dimensions having varying levels of significance to thriving. Although thriving has previously been mainly explored in long-term care settings for older people, thriving provides the unique perspective of situated contentment, focusing on factors that may support or hinder wellbeing in a specific environment. This study seeks to further the concept of thriving by exploring thriving in an independent living context, illuminating salient features to thriving in this specific context. By exploring thriving in sheltered housing, this study provides insight into the features specifically related to the expectations and reality, as well as the human and non-human interactions in the environment of sheltered housing, illuminating how features related to the context of sheltered housing influence situated contentment. 
In Sweden, sheltered housing is a relatively new form of housing for older people, which is designed to increase wellbeing among older people who feel anxious, socially isolated or unsafe ageing in place (Ministry of Health and Social Affairs, 2008). Sheltered housing in Sweden provides people over the age of 70 accessible apartments with access to communal spaces and increased opportunities for social participation, and Swedish sheltered housing accommodations commonly have a host or hostess, present certain hours of the week, whose main duty is to facilitate arranged social activities (Ministry of Health and Social Affairs, 2008). Swedish sheltered housing is intended for older people with relatively good health, as it is considered independent living (Ministry of Health and Social Affairs, 2008). In the establishing documents of Swedish sheltered housing, it is stated that the intention of this housing model is to promote quality of life and postpone care needs among the ageing population (Ministry of Health and Social Affairs, 2008). These benefits are presumed to be obtained by increasing social participation, as well as by providing an enhanced sense of security (Ministry of Health and Social Affairs, 2008). Swedish sheltered housing is ultimately anticipated to postpone or even prevent relocation, as these housings are designed so that one may remain in place despite decreasing mobility and health levels (Ministry of Health and Social Affairs, 2008). No health-care services are provided as part of residency in sheltered housing, although residents may be eligible to apply for home care services under the same conditions as older people residing in their own homes (Ministry of Health and Social Affairs, 2008). Accommodation in sheltered housing is generally allocated through the general housing queue, and residents therefore pay market-level rent (National Board of Health and Welfare, 2019a). As Swedish sheltered housing accommodations are often newly built buildings with services included, the rent is generally higher than the market-level rent for ordinary apartments (Senior Life, 2021). The monthly rent of a one-bedroom apartment in a sheltered housing accommodation in northern Sweden ranged from 5,700 to 9,530 SEK (approximately $€ 560-935$ or US $\$ 665-1,111$ ) in 2019, while the average monthly rent for a one-bedroom apartment in sparsely populated areas, such as northern Sweden, was 5,007 SEK (approximately $€ 495$ or US \$592) in 2019 (Home and Rent, 2019; Statistics Sweden, 2021). However, social services may assist in seeking financial assistance if eligibility requirements concerning wealth and income are fulfilled (National Board of Health and Welfare, 2019b). The conceptual design and intention of Swedish sheltered housing is to provide a solution to the increasing care needs, and associated costs, of the ageing population, by providing a supportive and health-promoting environment (Ministry of Health and Social Affairs, 2008).

Currently, studies concerning the wellbeing and thriving of residents in sheltered housing and similar housing types with a focus on social participation are scarce and varied. This scarcity and variation in the literature is partly due to national differences in the services offered in internationally comparable sheltered housing models, but also the conceptual inconsistencies concerning different terminology used to describe these types of housing models for older people, and in the Swedish context, the relatively new nature of this housing model for older people. Internationally, a directly comparable form of housing to Swedish sheltered housing is difficult to identify due to differences in welfare systems, conceptual 
descriptions and fiscal policies. Although various housing models for older people exist internationally, Swedish sheltered housing differs from international sheltered housing models by providing housing with elevated opportunities for social interaction and increased physical accessibility, but with no health-care services provided upon residency (Ministry of Health and Social Affairs, 2008). In Europe, such as in the United Kingdom (UK) and the Netherlands, sheltered housing is often defined as independent housing for older people which has a focus on providing social support, and is often a service provided by local authorities, although the amount of services and levels of support largely vary, with some offering healthcare services (van Bilsen et al., 2008; Egbu et al., 2011; Howe et al., 2013; Iecovich, 2016; Fox et al., 2017). Therefore, only studies where the housing model for older people has been clearly defined, and in which it has been found to be similar to Swedish sheltered housing (independent living, focus on social participation, accessible spaces, services or shared common rooms, little or no health-care services provided), have been included in the review of previous studies.

Previous international research has illuminated aspects of sheltered housing that are meaningful to resident wellbeing. A study from the Netherlands showed that residents reported higher perceived autonomy, sense of security and quality of life, and more frequent participation in social activities, compared to older people living independently in the community (van Bilsen et al., 2008). A study from the UK showed that the social aspects of sheltered housing were perceived as beneficial by residents, with stronger feelings of personal responsibility for their wellbeing due to support of the communal environment, although uncertainty concerning who entered the communal dwelling, and lack of information concerning services and how to access them were mentioned as barriers to wellbeing (Cook et al., 2016). An ethnographic study from the UK has shown that living in sheltered housing may result in both social closeness as well as social resistance, due to concerns about gossip and neighbours' perceptions (Percival, 2000), and a study of residents in the Netherlands affirmed that although those living in sheltered housing may socially interact with other people more often, the interaction may be limited and superficial in nature, again due to fear of gossip (Herbers and Meijering, 2015). Interviews of managers of nursing homes and sheltered housing in the UK, however, reported that few activities take place in these accommodations, and the options of activities arranged by the residents are usually lacking stimulation (such as having morning coffee or birthday parties), despite aspirations to mobilise residents to arrange activities (Gray and Worlledge, 2018).

A recent study from Sweden showed that residents felt living in a safe social context with people of the same age contributed to a safe peaceful environment, and being able to maintain independence due to the accessible spaces in sheltered housing was found to contribute to perceptions of safety (Lindahl et al., 2018). However, residents also reported security concerns regarding being potential victims of crime, as well as concerns about forcefully having to move due to potential shifts in their health and financial situation (Lindahl et al., 2018). Another recent study from Sweden found that residence in Swedish sheltered housing contributed to feelings of safety on a general level, but factors such as uncertainty concerning the amount of care provided in sheltered housing, health issues restricting residents from participating in activities, strangers congregating within the building and concerns 
related to neighbours with cognitive impairments caused unease among the residents (Berglund-Snodgrass and Nord, 2019). It has also been shown that residents in Swedish sheltered housing report lower levels of self-reported health, health-related quality of life and functional status, and higher depressive mood compared to those ageing in place (Corneliusson et al., 2019).

This study and article differs from the existing literature, as the intent of Swedish sheltered housing (as stated in governmental documents) is to provide a supportive environment that shall act as a facilitator of health and wellbeing, and no healthcare services are included upon residency in Swedish sheltered housing, while sheltered housing models in Europe generally include nearby, or on-site, staff and/or security alarms (Ministry of Health and Social Affairs, 2008; van Bilsen et al., 2008; Egbu et al., 2011; Iecovich, 2016; Fox et al., 2017). Furthermore, this study includes a novel focus on thriving as an existential life-world measure of lived experiences of situated contentment, while previous studies have mainly focused on illuminating factors related to general wellbeing while residing in sheltered housing. As previous quantitative study has that shown that with increasing levels of depressive mood and decreasing levels of self-rated health and functional status, those residing in sheltered housing report higher levels of thriving compared to those ageing in place (Corneliusson et al., 2020), the aim of this study was to illuminate aspects of sheltered housing that are facilitators and/or barriers to thriving, as described by residents living in Swedish sheltered housing. By exploring thriving, this study seeks to explicate the features which may influence situated contentment specifically in the context of Swedish sheltered housing. A further benefit of selecting thriving as the concept of interest in the Swedish setting is that thriving is commonly understood and used in the Swedish language as a concept denoting situated contentment (The Swedish Academy Dictionary, 2007), making thriving an easily understood concept in this context. This study is part of the larger Umeå ageing and health research programme (U-age), which explores person-centred care and health-promoting living conditions for the ageing population in Sweden (Umeå University, 2019). The U-age Sheltered Housing study specifically aims to compare health outcomes between sheltered housing and ageing in place.

\section{Methods}

\section{Design}

A descriptive design with semi-structured group interviews was used in this study. The COREQ criteria for reporting qualitative research was followed to ensure validity and rigour.

\section{Sampling and participants}

The U-age Sheltered Housing study comprises all sheltered housing accommodations $(\mathrm{N}=88)$ in Sweden, both public and private, registered in the National Board of Housing, Building and Planning's registries. Of these registered accommodations, 14 potential sheltered housing accommodations were identified based on geographical proximity for this study. Based on information available in the registry and online, the first author (LC) attempted to contact 14 sheltered housing accommodations via phone or email. Five of these potential sheltered housing 


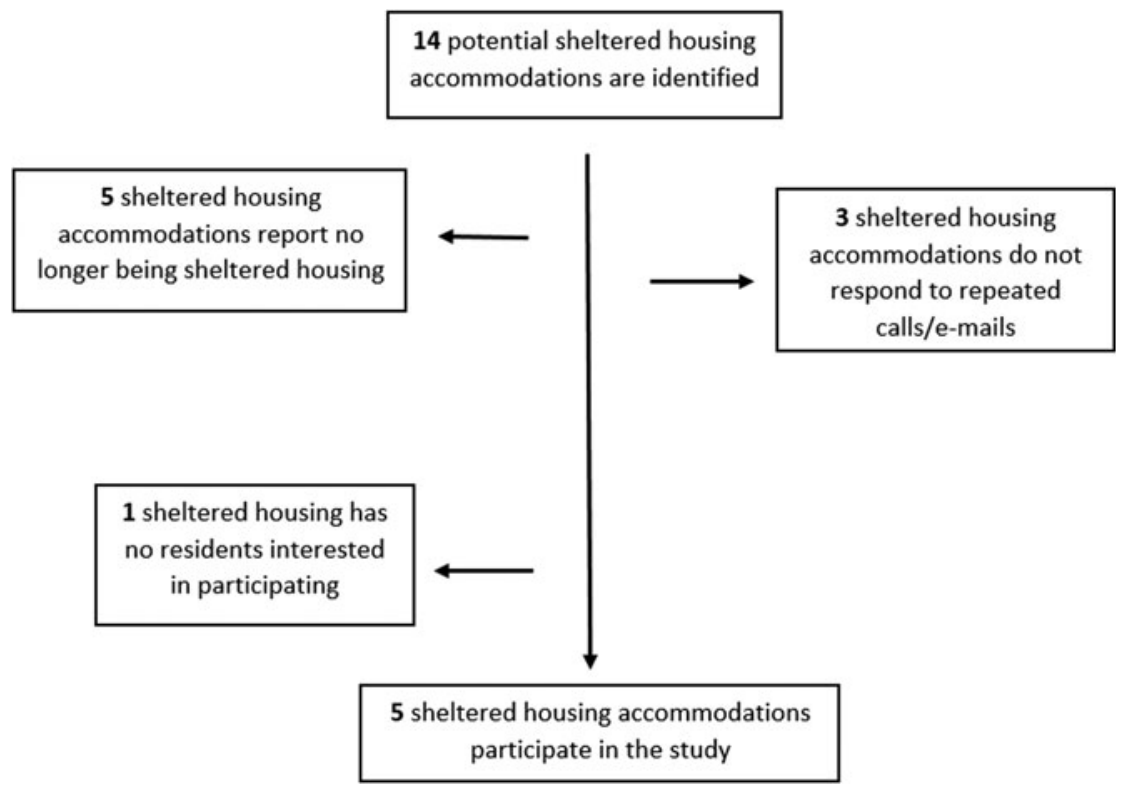

Figure 1. The data collection process.

accommodations had been converted into other types of senior housing facilities, and three did not respond to repeated calls or emails. Six hostesses/managers responded to the emails or phone calls and volunteered to assist in recruiting participants. The hostesses/managers informed the residents of the study by handing out an information letter, placing an invitation on the billboard and/or by personally inviting residents. One sheltered housing reported that they had no willing participants. The hostesses/managers of the five remaining sheltered housing accommodations assisted in informing the residents of the time of the interview and booked facilities for the group interviews. The final sample consisted of two sheltered housing accommodations in northern Sweden and three in central Sweden (see Figure 1). The inclusion criteria for this study was residence in sheltered housing. Due to the challenges in contacting residents, all willing participants in the five sheltered housing accommodations were included in the study, resulting in a convenience sample of the population residing in sheltered housing.

The final sample consisted of 38 residents, 28 women and ten men, living in five different sheltered housing accommodations. In all, seven group interviews were conducted, with four to nine participants in each group, between April 2019 and January 2020. The participants had resided in sheltered housing from 1 month to $8 \frac{1}{2}$ years. The youngest participant was 73 and the oldest participant was 96 .

\section{Data collection}

All the interviews were conducted by LC and KS, except for one which was conducted by LC and AS. The interview guide consisted of open-ended questions: the participants were first asked how they thrive in sheltered housing, and then 
asked to elaborate on their responses. Follow-up questions were guided by the residents responses, and consisted of questions related to the services provided, the staff and expectations residents had of sheltered housing; the follow-up questions were inspired by previous quantitative and qualitative studies on thriving and the TOPAS instrument, which have shown aspects such as services, staff and expectations are meaningful to thriving (Bergland and Kirkevold, 2006; Björk et al., 2017). The residents were also asked to list factors that facilitate and obstruct thriving while living in sheltered housing. All interviews were conducted in the group rooms within the sheltered housing accommodations. The duration of the interviews ranged from 45 minutes to 1 hour 15 minutes. There were no prior relationships between the interviewers and the residents who participated in this study.

\section{Data analysis}

Each group interview was tape recorded and transcribed into text. Qualitative content analysis was used for analysing the data. An inductive approach, in which similarities and differences were compared to identify emerging categories (Graneheim et al., 2017), was utilised to determine factors that promote or hinder thriving in sheltered housing. First, each interview was read multiple times to obtain an overall understanding of the content of the interviews. The interviews were then read with a focus on identifying statements regarding elements of sheltered housing that was experienced to either facilitate or obstruct thriving, with the coding framework emerging inductively. These statements were written in the margins by LC as short statements, mainly in gerund form, to form initial codes. The codes were then listed in a separate document, grouping the codes into elements that either facilitate or obstruct thriving. All the codes from all the interviews were then compared through analytical discussions involving the whole research team, with similar codes being merged and sub-categories being identified. The sub-categories were formed by identifying statements that emerged from the data, linking similar statements into cohesive categories. Finally, the whole research group reached consensus concerning the sub-categories that were deductively organised into main categories, based on a model inspired by Grol and Wensing (2004). These four main categories illuminate the different levels of the facilitators and barriers to thriving: the individual factors, the social context, environmental factors and the organisational context (Grol and Wensing, 2004).

\section{Ethical considerations}

All participants received both written and oral information on the aims of the study and the interviewers, and informed consent was obtained orally from the residents. Participants were informed that participation is voluntary, that they may withdraw at any point of time without justification or consequences, and that the results will be anonymised. The study was approved by the Regional Ethical Review Board in Umeå, Sweden.

\section{Results}

The four main categories illuminate the different levels of the facilitators and barriers to thriving: individual factors, social context, environmental factors and 
Table 2. Facilitators and barriers to thriving in Swedish sheltered housing - main categories

\begin{tabular}{|c|c|c|}
\hline \multirow[b]{2}{*}{ Main category } & \multicolumn{2}{|c|}{ Dimensions } \\
\hline & Facilitators to thriving & Barriers to thriving \\
\hline Individual factors & $\begin{array}{l}\text { - Having a positive attitude } \\
\text { - Having opportunities to } \\
\text { preserve autonomy }\end{array}$ & $\begin{array}{l}\text { - Having declining health } \\
\text { - Having unmet expectations }\end{array}$ \\
\hline Social context & $\begin{array}{l}\text { - Perceiving organised support } \\
\text { - Perceiving informal support } \\
\text { - Perceiving a positive social } \\
\text { climate }\end{array}$ & $\begin{array}{l}\text { - Perceiving social tensions } \\
\text { - Perceiving declining health } \\
\text { of neighbours }\end{array}$ \\
\hline $\begin{array}{l}\text { Environmental } \\
\text { factors }\end{array}$ & $\begin{array}{l}\text { - Living in an accessible } \\
\text { environment } \\
\text { - Living in an aesthetically } \\
\text { pleasant and peaceful } \\
\text { environment } \\
\text { - Living close to services and } \\
\text { public transport }\end{array}$ & $\begin{array}{l}\text { - Living in an impractical and } \\
\text { uninspiring environment } \\
\text { - Living in an unsafe } \\
\text { environment }\end{array}$ \\
\hline $\begin{array}{l}\text { Organisational } \\
\text { context }\end{array}$ & $\begin{array}{l}\text { - Experiencing shared activities } \\
\text { - Experiencing arenas for } \\
\text { spontaneous social interaction }\end{array}$ & $\begin{array}{l}\text { - Experiencing limited } \\
\text { provision of services } \\
\text { - Experiencing not being } \\
\text { heard } \\
\text { - Experiencing high cost of } \\
\text { rent }\end{array}$ \\
\hline
\end{tabular}

organisational context. In total, ten facilitators and nine barriers to thriving in sheltered housing were identified (Table 2).

\section{Individual factors}

The category individual factors was found to have two dimensions that facilitated thriving in sheltered housing, namely having a positive attitude and having opportunities to preserve autonomy (Table 3 ). Having a positive attitude, described as seeing the positive aspects of things, making the best of the situation one is in and adapting one's attitude depending on the situation, helped residents thrive and was described as a facilitator of thriving. This was exemplified by, for example, acknowledging personality differences between people and striving to get along nonetheless; or, as seeing the corridors, which were described as long and aesthetically non-inspirational, as a good place for exercise, as illuminated below:

And then these corridors that look so boring - but what great exercise it is!

Having opportunities to preserve autonomy, such as not feeling socially obliged to interact with neighbours, was a feature that was described as significant to thriving. Autonomy was described as the opportunity to choose how much time one wants to spend with others, and the opportunity to remain in the privacy of one's 
Table 3. Sub-categories of individual factors influencing thriving in sheltered housing

\begin{tabular}{ll}
\hline & \multicolumn{1}{c}{ Individual factors } \\
\hline Facilitators to thriving & Barriers to thriving \\
\hline Having a positive attitude: & Having declining health: \\
- Seeing the positive aspects of things & - Not being able to participate in activities to \\
- Making the best of the situation one & the extent one wishes to \\
is in & - Fear of not managing alone \\
- Adapting one's attitude & - Fear of being a burden to others \\
$\begin{array}{ll}\text { Having opportunities to preserve } & \text { - Fear of needing to relocate due to increasing } \\
\text { autonomy: } & \text { care needs } \\
\text { - Not feeling socially obliged to } & \text { Having unmet expectations: } \\
\text { interact with neighbours } & \text { - Residents moving in expecting health-care } \\
\text { - Having the opportunity to choose } & \text { services } \\
\text { how much time one wants to spend } & \text { - General public equating sheltered housing to } \\
\text { with others } & \text { nursing homes } \\
\text { - Having the opportunity to remain in } & \text { Disappointment in the eligibility } \\
\text { the privacy of one's apartment when } & \text { requirements; residents moving in that are } \\
\text { so desired } & \text { perceived as having little interest in, or need } \\
\text { for, social interaction }\end{array}$ \\
\end{tabular}

apartment when so desired, without others in the community being offended or upset. This opportunity to preserve autonomy, and the support and understanding of others in the community towards this need for privacy, was described as meaningful to thriving while residing in sheltered housing, as depicted below:

Another thing I would like to say, it's that it's neutral here. So no requirements that one has to come here, you do what you like, it's a type of freedom, and I think that it's very good that you can decide yourself, without feeling pressured to go there and have coffee, but instead go when you feel like it and want to meet your neighbours.

The category individual factors was found to have two dimensions that obstructed thriving in sheltered housing, namely having declining health and having unmet expectations. Due to having declining health, residents reported not being able to participate in activities to the extent that they wished to, as well as expressed fear that they will not manage alone and be a burden to others. Residents feared that with increasing care needs they may need to relocate, which was a concern that impacted thriving negatively.

When we moved in here, we were a lot more energetic. Everything was nice and fun, but it's the same for us as for everyone else who gets older, there will be sickness and ailments, it becomes a bit harder.

Having unmet expectations was described as misunderstandings concerning the provision of health-care services, and not having social expectations met. Misunderstandings concerning the provision of health-care services in sheltered housing, with residents moving in expecting health-care services and not receiving the care they needed, as well as the general public assuming sheltered housing is similar to 
Table 4. Sub-categories of factors within the social context influencing thriving in sheltered housing

\begin{tabular}{|c|c|}
\hline \multicolumn{2}{|c|}{ Social context } \\
\hline Facilitators to thriving & Barriers to thriving \\
\hline $\begin{array}{l}\text { Perceiving organised support: } \\
\text { - Perceived easy access to home care } \\
\text { services and assistance from the hostess } \\
\text { - Having an engaged and helpful hostess } \\
\text { - Having a wide selection of arranged } \\
\text { activities } \\
\text { - Being able to influence the selection of } \\
\text { activities } \\
\text { - Having familiar home care service staff } \\
\text { Perceiving informal support: } \\
\text { - Being close to family } \\
\text { - Assistance from volunteers and } \\
\text { volunteering } \\
\text { - Assisting and helping neighbours with } \\
\text { practical matters } \\
\text { Perceiving a positive social climate: } \\
\text { - Knowing neighbours } \\
\text { - Feeling welcomed } \\
\text { - Enjoying each other's company }\end{array}$ & $\begin{array}{l}\text { Perceiving social tensions: } \\
\text { - Disputes with neighbours } \\
\text { - Fear of being the subject of gossip } \\
\text { - Fear of being left outside the group } \\
\text { - Language barriers } \\
\text { Perceiving declining health of neighbours: } \\
\text { - Concern over neighbours' care needs } \\
\text { being met } \\
\text { - Neighbours' inability to participate in } \\
\text { activities due to declining health }\end{array}$ \\
\hline
\end{tabular}

nursing homes, impacted thriving negatively. Public misconceptions of sheltered housing, with the acquaintances of residents equating sheltered housing to nursing homes, and with residents moving in expecting health-care services, bothered residents, as residents underlined that sheltered housing is independent living where residents live independently in their own apartments. Residents expressed disappointment in the eligibility requirements for moving into sheltered housing, as need for social interaction is currently not a universal eligibility requirement, and apartments are distributed based on time in the general housing queue. These guidelines resulted in residents moving in that were perceived as having little interest in, or need for, socially interacting with fellow residents, which was experienced as a hindrance to thriving for residents that expected more social engagement. Below are two quotations illuminating the unmet expectations residents encountered while residing in sheltered housing:

I think someone moved in and thought this was a completely different type of housing. Because when I went over to say 'Hi and welcome', she said 'when will the nurse come?'

And I think when you move into sheltered housing, you should have a need for this type of community. It should actually be the first criterion, that's how I see it. Not the time in line. That's what really bothers me.

\section{Social context}

The category social context consisted of three dimensions that facilitated thriving in sheltered housing, namely perceiving organised support, perceiving informal support and perceiving a positive social climate (Table 4). Perceiving organised support was 
described as having the opportunity to access organised support and assistance from either a hostess at the sheltered housing (which all sheltered housing arrangements that participated in this study offered), or from home care staff. Having an engaged and helpful hostess that provided a wide selection of arranged activities, and being able to influence the selection of activities arranged by the hostess, was appreciated by residents and was described as a contributor to thriving. Especially, the perceived easy access to home care services and the availability of a hostess for assistance in practical matters was perceived as an element that supported the possibility to remain in sheltered housing despite declining health. Residents receiving home care services described having familiar care takers, and the sense of continuity it offered, as meaningful to thriving in sheltered housing, and believed that living in an area in which many received home care services facilitated easier access to familiar home care staff, as exemplified below:

They say that in some places there can be 20 different [home care staff members] that come and go, but here we have almost always the same, it's almost always two girls and one guy that come.

Perceiving informal support, such as receiving support from family members or fellow residents, was reported as a contributor to thriving. Residents reported having chosen to move to sheltered housing to be close to family members, and found engaging socially with family members as meaningful to thriving. Residents commonly reported supporting each other by either volunteering, or assisting and helping neighbours with practical matters. Volunteers from within the sheltered housing accommodations helped the community by organising activities, decorating the common areas and welcoming new neighbours. Looking after each other, assisting each other and being able to face the challenges of ageing together was described as a factor that contributed to thriving, as well as provided security and a sense of community, as one could trust that if one needs assistance or if something seems wrong, neighbours would react, as narrated below:

And not to mention the neighbours, they are the security here. The neighbours. We are all in the same boat.

We look after each other here, if I need help I can go over to somebody and they will help me. That's the way it is.

Perceiving a positive social climate was described as, for example, knowing and greeting neighbours, feeling welcomed and enjoying each other's company. For many remaining in the same area and being close to where one had previously lived, and thereby being acquainted with the surroundings and other residents, reinforced the experience of having a positive social climate. Being acquainted with fellow residents and feeling welcomed into the community encouraged social interaction, which facilitated a perceived positive social climate and promoted thriving, as described below:

Yes, and we realised that we wouldn't have the strength [to remain living at home], and I must say we moved at the right time. And then when we moved in here we 
said it is the best thing we have done ... You came into the apartment, and our apartment is great. And the community. One was welcomed into the group immediately. Everything worked.

The category social context was found to have two dimensions that obstructed thriving in sheltered housing, namely perceiving social tensions and perceiving declining health of neighbours. Perceiving social tensions, such as disputes, fear of being the subject of gossip, fear of being left outside the group and language barriers were described as factors that hindered thriving. Cliques consisting of residents that had resided in the sheltered housing for a longer time caused concern in residents that had recently moved in, as cliques were perceived as difficult to approach, and residents feared being left out of the group. Residents also expressed a desire to have shared cultural values and a shared language with fellow residents; this desire was attributed to a personal interest in engaging socially with all the residents in the community, to a concern of isolation for people experiencing language barriers, or to a fear of social tensions arising due to miscommunication. Below are quotations illuminating the perceived social tensions residents experienced while residing in sheltered housing:

Yes, it could be a little more open, more welcoming, open conversations. Because when you come in as a new person, then you don't know, you sit in a closed group in here, you almost feel like an intruder, I can vouch for that.

I don't know, I have never had people around me where I have lived. So when I moved here I thought ... 'No, everyone's staring at me', 'Where is she going now? What is she going to do now? It's starting to pass now though (laughter).

Perceiving declining health of neighbours caused concern in residents and was reported as a hindrance to thriving. Residents experienced a lack of knowledge concerning who has the responsibility for the care of neighbours with declining health, and the uncertainty related to the extent of care neighbours needed and received care evoked stress in residents. Neighbours who were perceived as having developed extensive care needs were a source of worry regarding if their needs were being met. Neighbours with declining health also had limited opportunities to participate in social activities, which was perceived as a hindrance for thriving, as residents desired to include the whole community in the activities:

And as said, we have an older man who is 96 who lives over there. Lying there alone all day. I've spoken to the sons, asked 'What should we do?' And they don't care about their father.

It has become like a nursing home here. And it's a bit boring, because they never come to anything, and they don't have the strength to either.

\section{Environmental factors}

The category environmental factors was found to have three dimensions that contributed to thriving in sheltered housing, namely living in an accessible environment, living in an aesthetically pleasant and peaceful environment and living close 
Table 5. Sub-categories of environmental factors influencing thriving in sheltered housing

\begin{tabular}{|c|c|}
\hline \multicolumn{2}{|c|}{ Environmental factors } \\
\hline Facilitators to thriving & Barriers to thriving \\
\hline $\begin{array}{l}\text { Living in an accessible environment: } \\
\text { - Features such as elevators, no or low } \\
\text { thresholds, stoves with auto-shutdown, } \\
\text { and apartments and corridors with wide } \\
\text { rooms and doors enabling wheelchair } \\
\text { access } \\
\text { - The maintenance of the apartments and } \\
\text { common areas } \\
\text { - Considerations towards the needs of older } \\
\text { adults, such as having warmer apartments } \\
\text { Living in an aesthetically pleasant and peaceful } \\
\text { environment: } \\
\text { - Being close to the woods or water } \\
\text { - Having flowers and gardens within, and } \\
\text { around, the sheltered housing } \\
\text { accommodation } \\
\text { - Having new, or newly renovated, } \\
\text { apartments, with spacious rooms and new } \\
\text { and modern appliances } \\
\text { Living close to services and public transport: } \\
\text { - Access to laundry rooms, places to } \\
\text { barbecue, saunas, gyms, and guest rooms } \\
\text { for friends and family } \\
\text { - Being close to public transport and } \\
\text { services, such as a bus stop, grocery store } \\
\text { or health-care centre } \\
\text { - Having access to gym equipment } \\
\text { Having walking paths in the vicinity }\end{array}$ & $\begin{array}{l}\text { Living in an impractical and uninspiring } \\
\text { environment: } \\
\text { - Inadequate consideration to } \\
\text { accessibility, such as placement of } \\
\text { cupboards too high up, difficult } \\
\text { placement, or lack of, storage space, } \\
\text { high thresholds in the apartments, } \\
\text { narrow doors and small common rooms } \\
\text { - Lack of indoor walkways connecting } \\
\text { buildings } \\
\text { - Long distances to services and public } \\
\text { transport } \\
\text { - Perceiving an uninspiring environment, } \\
\text { e.g. having few decorations, plants or } \\
\text { paintings in the common areas and } \\
\text { corridors } \\
\text { Living in an unsafe environment: } \\
\text { - Lacking personal security alarms } \\
\text { - Slow maintenance of broken doors } \\
\text { - Broken fire alarms } \\
\text { - Items from the common areas being } \\
\text { stolen or destroyed } \\
\text { - Societal restlessness, with problems } \\
\text { relating to littering, loud noises and } \\
\text { crime } \\
\text { - Too good sound isolation }\end{array}$ \\
\hline
\end{tabular}

to services and public transport (Table 5). Living in an accessible environment, with features such as elevators, no or low thresholds, stoves with auto-shutdown, and apartments and corridors with wide rooms and doors enabling wheelchair access, were described as factors that contributed to thriving. The residents perceived these aspects as qualities that promoted their opportunity to remain able, autonomous and safe, and therefore remain living in the sheltered housing despite declining health. The maintenance of the apartments and common areas, as well as consideration towards the needs of older adults, such as having warmer apartments, were furthermore features that were appreciated by residents, and which promoted thriving in sheltered housing:

I thrived here from the beginning, because where I came from, there we had a spiral staircase. And hadn't I been able to move in here, then I would have not been able to go out. So I was lucky that I could come here.

And we meet now and again in the corridors, or here downstairs, and its actually quite fun. You meet new people. We have felt that it is good, and we don't have to shovel the snow or mow the lawn. And the apartments are accessible. 
Living in an aesthetically pleasant and peaceful environment was described by residents as, for example, being close to the woods or water, as well as having flowers and gardens within and around the sheltered housing. Residents also reported enjoying having new, or newly renovated, apartments, with spacious rooms and new and modern appliances. These qualities in the environment were experienced as pleasant and welcoming, and were reported to be facilitators to thriving. Residents appreciated having a nice view from the apartments, such as being able to see nature or a river from the apartments, as well as living in a peaceful area, as illustrated below:

It's so calm and peaceful here. We have no need for hullabaloo.

As many residents either had, or expected, decreasing mobility, living close to services and public transport was described as an important factor that contributed to thriving through continued opportunities to interact socially with loved ones and take care of practical matters. The services provided within sheltered housing, such as access to laundry rooms, places to barbecue, saunas, gyms, and guest rooms for friends and family, provided increased opportunities for social interaction, as well as made life easier and more practical for the residents. Being close to public transport and services, such as a bus stop, grocery store or healthcare centre, was experienced as facilitating opportunities to remain active and autonomous. Having access to gym equipment, as well as having walking paths in the vicinity, were reported as meaningful to thriving, as these provided the residents with opportunities to maintain health and remain able, which thereby also promoted thriving, as described below:

And when you are mobile you can yourself influence thriving a lot. To commit to thriving. But then you don't know, it can shift from one day to another. And especially if you are afraid of being a burden. It's hard to think of the future.

There were people who asked me how I could move in here, and then I mentioned this, it's 50 metres to the health-care centre, 75 metres to the grocery store, 100 metres to the liquor store and in the other direction it's 300 metres to the cemetery. Everything is a crawling distance away.

The category environmental factors was found to have two dimensions that obstructed thriving in sheltered housing, namely living in an impractical and uninspiring environment and living in an unsafe environment. Living in an impractical and uninspiring environment was described as inadequate consideration to accessibility, exemplified by the placement of cupboards too high up, difficult placement, or lack of, storage space, high thresholds in the apartments, narrow doors, small common rooms and a lack of indoor walkways connecting buildings to avoid having to go outside in the winter. Residents in sheltered housing in sparsely populated areas found the distance to services and public transport to be problematic, and expressed a desire for having a bus to the grocery store every fortnight. Perceiving an uninspiring environment, e.g. having few decorations, plants or paintings in the common areas and corridors, resulted in an institution-like atmosphere, which hindered thriving: 
Table 6. Sub-categories of factors within the organisational context influencing thriving in sheltered housing

Organisational context

Facilitators to thriving

Barriers to thriving

Experiencing shared activities:

- Having the opportunity to participate in activities managed or supported by staff of sheltered housing

- Having the opportunity to participate in activities such as eating together, having wine tastings, playing bingo or reading

Experiencing arenas for spontaneous social interaction:

- Having access to common rooms

- Having opportunities for casual encounters in the corridors, the common rooms or dining rooms
Experiencing limited provision of services:

- Disappointment in the amount of activities provided

- Disappointment in the restricted amount of time together with the hostess

Experiencing not being heard:

- Lacking provision of information

- Having changing staff

- Feeling the residents' voices are not being heard

- Having services restricted due to cutbacks

Experiencing high cost of rent:

- Fear of not being able to continue living in sheltered housing due to the high cost of rent

They think old people don't have any clothes, we have no storage, we don't need any.

The first day I came here and looked and the corridor, it was like 'Oh, I am in a hotel.' My sister who was with me said: 'Oh my God, this is a hospital.' That was her impression of the long corridor. You [neighbour] have some flowers, but you put them there yourself.

Living in an unsafe environment, lacking personal security alarms, slow maintenance of broken doors and broken fire alarms, hindered thriving. Items from the common areas being ruined, such as Christmas decorations, flowers and decorations being stolen or destroyed, hindered thriving. Residents living in sheltered housing situated in areas with societal restlessness, with problems relating to littering, loud noises and crime, reported concerns related to safety while visiting outside the sheltered housing residence. Slow maintenance, such as delayed snow ploughing or slow repair of broken elevators, was described as restricting residents' opportunities to remain mobile. Too good sound isolation in the apartments was reported as both promoting and obstructing thriving; although many enjoyed good sound isolation, there was fear, and some experiences, of not being heard in cases of emergencies, as illustrated below:

You notice that the sound isolation is good. I fell last December, and was lying on the floor for three days. Nobody heard me.

\section{Organisational context}

The category organisational context was found to have two dimensions that contributed to thriving in sheltered housing, namely experiencing shared activities and experiencing arenas for spontaneous social interaction (Table 6). Experiencing 
shared activities was described as having the opportunity to participate in activities managed or supported by staff of sheltered housing; the activities were arranged either by the hostess, or by volunteers from within the sheltered housing with the support of the hostess. Experiencing shared activities, such as eating together, having wine tastings, playing bingo or reading together were described as meaningful to thriving in sheltered housing, as residents appreciated having organised opportunities to socialise with other residents:

I thrive well when I can sit like this, when we are sitting and painting and we can joke around.

Experiencing arenas for spontaneous interaction, such as having access to common rooms where one could find company when one so desires, was reported as a contributor to thriving. The design of the sheltered housing supported opportunities for casual contact with neighbours, as the sheltered housing provided and maintained areas designated for social interaction, and being able to interact socially with others when so desired was described as a factor that helped pass time and facilitated thriving. Having arenas to meet fellow residents, such as having opportunities to experience casual encounters in the corridors, the common rooms or dining rooms, alleviated loneliness, as illuminated below:

And right before I moved in here it was hard for me to move outside and I had been very isolated, so I actually lost my voice. I didn't speak for several days, still haven't really gotten it back. So I am very happy that there is an opportunity to meet people when you have a need for it.

And we sometimes meet up here, sometimes in the corridors, but you always have someone to talk to. And so time passes, and I think it's really good.

The category organisational factors was found to have three dimensions that obstructed thriving in sheltered housing, namely experiencing limited provision of services, experiencing not being heard and experiencing high cost of rent. Experiencing limited provision of services was described as disappointment in the amount of activities provided, and disappointment in the restricted amount of time together with the hostess. The limited selection of arranged activities, and especially the lack of the arranged opportunity to eat together, were perceived as factors that hindered thriving. Residents also desired more time together with the hostess, and increased opportunities for the hostesses to arrange more activities:

What is still really boring, it's eating alone. Of course, you could eat together - you can, just take your plate with you, but we don't have any organised food lady here.

Experiencing not being heard in sheltered housing was described as lacking provision of information, having changing staff, feeling the residents' voices are not being heard and having services restricted due to cutbacks. The general lack of information concerning matters relevant to the residents, such as lacking information concerning the change of management and changing services, as well as not 
being welcomed by the hostess when moving in, was described as a hindrance for thriving. Having changing and unfamiliar hostesses, who were not familiar with the residents and routines, resulted in a lack of a sense of continuity and hindered thriving. Residents also reported feeling as though they were dismissed and not heard by the management, especially when it came to cutbacks and changes in services. The rearranging of the duties of the hostesses, restricting the amount of hours the hostesses are present and reducing the amount of activities due to cutbacks evoked agitation and disappointment in the residents, as changes were implemented despite residents' objections:

I've lived here for three years, and there was no one who welcomed me when I came here the first time, and it felt very strange. When you don't know anything, no one explained what this [place] is, I didn't know then.

And what's wrong, if we shall talk about wrong, is those who sit in the office, okay they have a lot to do. They come here and put up an announcement, they don't come and check what we are doing, or knock on our door to see how we are doing, not at all. Instead they think that doesn't concern them.

Experiencing high cost of rent while residing in sheltered housing resulted in financial concerns, and fear of having to relocate due to financial struggles was experienced as a hindrance to thriving. Residents expressed that, although they desired to remain in sheltered housing, they felt they may not be able to continue living in sheltered housing due to the high cost of rent, and mentioned the stress related to the high cost of rent as a hindrance to thriving:

I'm going to move. Because the rent is so expensive, I can't afford to live here.

\section{Discussion}

The aim of this study was to illuminate aspects of sheltered housing that are facilitators and/or barriers to thriving (understood as lived experiences of situated contentment), as described by residents living in Swedish sheltered housing, and the findings showed how barriers and facilitators to thriving can be found at individual, social, environmental and organisational levels. At an individual level, previous studies on Swedish sheltered housing have reported concerns among residents living in sheltered housing related to declining health and potentially arising healthcare-related needs (Lindahl et al., 2018; Berglund-Snodgrass and Nord, 2019), and these concerns were reiterated throughout the results of this study. The influence of declining health to thriving was highlighted in the results on the individual level; the emphasis on autonomy, remaining autonomous, and general concerns related to declining health and unmet expectations concerning the services provided illuminate health concerns related to the future, as well as seem to indicate a desire for more comprehensive support. These results also seem to imply that continuity may be a facilitator to thriving, although further studies are needed to verify this hypothesis. Having a positive attitude was also reported as a facilitator to thriving on the individual level, and a study in the nursing home setting found mental attitude to be the most influential aspect to thriving 
in the nursing home setting (Bergland and Kirkevold, 2006). Interestingly, the emphasis of different dimensions varied in the resident descriptions in the results of this study, with some dimensions being interconnected, e.g. participating in activities could be dependent on the functional status of residents, which also then may have affected the mental attitude one had, implying a hierarchy of dimensions in relation to thriving in sheltered housing. It is possible that the interconnectedness and varying emphasis of different dimensions can be explained by differences in physical mobility, personality, support networks and expectations.

At a social level, previous international studies have revealed that the social context provided in sheltered housing contributes to a sense of security and a stronger feeling of personal responsibility to maintain wellbeing (Cook et al., 2016; Lindahl et al., 2018), but may also result in superficial relationships due to concerns related to gossip (Percival, 2000; Herbers and Meijerling, 2015). The results of this study related to the social context revealed social tensions as a hindrance to thriving, but also highlighted the significance of positive relationships between residents, illustrated by the reciprocal help received in sheltered housing, as well as the concerns towards neighbours' declining health. The results related to the social context seem to again illuminate a desire for support and consideration towards health-related needs, exemplified by the importance of receiving formal and informal support. Although the concerns related to the health of neighbours may also reflect personal concerns related to the future and the level of support one will receive, this result seems to amplify the importance of the social context and the support provided, as the result underlines the significance of different levels of support received within the social context. Furthermore, descriptions of not receiving help during medical emergencies, such as when falling, illuminate the need for further consideration towards the varying levels of health residents in sheltered housing experience. Although residents moving into sheltered housing are expected to be capable of independent living, increasing age is associated with declining health, and the results of this study reveal a discrepancy between the level of support provided and the actual needs of residents. Although the results of this study illuminate that the supportive environment within sheltered housing seems to contribute to thriving, further research into the imbalance between the support needs of the residents and the services provided in sheltered housing are needed to ensure adequate support and optimal thriving while residing in sheltered housing.

At the environmental level, being protected from crime, unwanted persons, troublesome neighbours and evacuation has previously been found to be meaningful to residents in Swedish sheltered housing as this contributed to a sense of security (Lindahl et al., 2018), and the results of this study revealed that environmental aspects affected sense of security and opportunities to remain autonomous, especially as residents expected, or experienced, mobility issues. However, residents also described a desire for more consideration towards the specific needs of older people, such as improved accessibility, faster maintenance, protection from crime and security alarms in case of emergencies. Therefore, it seems future policies and practice should address the specific age-related needs within the environmental context, to ensure a sense of security and thereby better promote resident thriving.

At the organisational level, previous studies have shown that the lack of information concerning services and how to access them are barriers to wellbeing while 
residing in sheltered housing (Cook et al., 2016), as well as revealed a fear of having to relocate due to financial concerns (Lindahl et al., 2018). The results of this study on an organisational level indicate that although the services provided in sheltered housing are found to be beneficial, there seems to be a discrepancy between the services provided, the expectations of the residents and the information provided by the organisations. These results expose a desire for more information and shared decision making while residing in sheltered housing, as well as more extensive services and/or lower rent. Therefore, it seems that future development of sheltered housing should address the discrepancies and miscommunication between resident expectations and the services and information provided by proprietors of sheltered housing accommodations. Specifically, the dichotomy of sheltered housing being independent living, but consisting of ageing residents receiving home care services, warrants further exploration into how living in sheltered housing with, or among others with, health-care needs influences thriving. Furthermore, as the concept of sheltered housing is not protected by law but rather requirements are based on if the proprietor has received financial assistance, there seems to be a need for clarification concerning what sheltered housing accommodations provide, for whom are they intended and on what basis residency is allocated. Especially as sheltered housing is considered independent living, it seems more information should be provided to current, and potential, residents of sheltered housing on the amount of support provided while residing in sheltered housing, as well as information on where one can turn to when more comprehensive support needs arise. Further research into which means of communication are used to inform residents living in sheltered housing and how different communication means, such as digital communication methods, are experienced among those residing in Swedish sheltered housing could assist in ensuring residents are provided with accurate and accessible information.

\section{Conclusions}

The results of this study illuminate the multifaceted, and often interconnected, dimensions that influence thriving while residing in Swedish sheltered housing, displaying how thriving is an interplay between individual, social, environmental and organisational factors. Although the supportive environment provided in sheltered housing seems to contribute to thriving, the lack of continuity and consideration towards the shifting health of residents may be a barrier to thriving. The results of this study also imply that there may be a hierarchy within the dimensions related to thriving. Further studies are needed to explore the interconnectedness and emphasis of different dimensions to thriving in the sheltered housing context, the effects of the discrepancy between resident expectations and services provided in sheltered housing to thriving, and the significance of continuity to thriving. Nonetheless, the results of this study may assist in implementing tailored interventions to help support and facilitate thriving on the individual, social, environmental and organisational levels while residing in sheltered housing, as well as provide policy makers with knowledge on the factors within sheltered housing that need to be addressed to best promote resident thriving. 


\section{Limitations}

As the interviews were conducted in groups, it is possible that the respondents described views and opinions that are deemed socially desirable. Also, as the interviews were held in the common room areas, there is a risk that the participants who participated in this study were the residents with sufficient functional ability to assemble in the common areas. As this study utilised convenience sampling, there may be a bias towards those residents inclined towards being more socially active being the ones to participate in the study. It is therefore possible that this study mainly represents the experiences of the healthier and more socially active population residing in sheltered housing.

Acknowledgements. We would like to thank the hostesses of the sheltered housing accommodations that participated in this study for assisting in recruiting participants and arranging rooms in which to conduct the interviews. We would also like to thank all participants who took part in this study for sharing their experiences.

Financial support. This work was supported by The Swedish Research Council for Health, Working Life, and Welfare: FORTE (2014-4016); and The Swedish Research Council (521-2014-2715).

Author contributions. DE designed and directed the project. LC, KS and AS conducted the interviews. LC wrote the manuscript with support from KS, AS and DE. DE, KS and AS supervised the project.

Conflict of interest. The authors declare no conflicts of interest.

Ethical standards. The study was approved by the Regional Ethical Review Board in Umeå, Sweden (Dnr 2018/341-32).

\section{References}

Baxter R, Corneliusson L, Björk S, Kloos N and Edvardsson D (2021) A recipe for thriving in nursing homes: a meta-synthesis. Journal of Advanced Nursing 77, 2680-2688.

Bergland Å and Kirkevold M (2006) Thriving in nursing homes in Norway: contributing aspects described by residents. International Journal of Nursing Studies 43, 681-691.

Bergland Å, Kirkevold M, Sandman PO, Hofoss D and Edvardsson D (2015) The Thriving of Older People Assessment Scale: validity and reliability assessments. Journal of Advanced Nursing 71, 942-951.

Berglund-Snodgrass L and Nord C (2019) The continuation of dwelling: safety as a situated effect of multi-actor interactions within extra-care housing in Sweden. Journal of Housing for the Elderly 33, 173-188.

Björk S, Lindkvist M, Wimo A, Juthberg C, Bergland Å and Edvardsson D (2017) Residents' engagement in everyday activities and its association with thriving in nursing homes. Journal of Advanced Nursing 73, 1884-1895.

Cook G, Bailey C, Hodgson P, Gray J, Barron E, McMillan C, Marston R, Binks E and Rose J (2016) Older UK sheltered housing tenants' perceptions of well-being and their usage of hospital services. Health and Social Care in the Community 25, 1644-1654.

Corneliusson L, Sköldunger A, Sjögren K, Lövheim H, Wimo A, Winblad B, Sandman PO and Edvardsson D (2019) Residing in sheltered housing versus aging in place - population characteristics, health status and social participation. Health and Social Care in the Community 27, e313-e322.

Corneliusson L, Sköldunger A, Sjögren K, Lövheim H, Lindkvist M, Wimo A, Winblad B, Sandman P-O and Edvardsson D (2020) Well-being and thriving in sheltered housing versus ageing in place: results from the U-age sheltered housing study. Journal of Advanced Nursing 76, 856-866.

Edvardsson D, Baxter R, Corneliusson L, Anderson RA, Beeber A, Boas PV, Corazzini K, Gordon AL, Hanratty B, Jacinto A, Lepore M, Leung AYM, McGilton KS, Meyer J, Schols JMGA, Schwarts L, Shepherd V, Sköldunger A, Thompson R, Toles M, Wachholz P, Wang J, Wu B and Zúñiga $F$ (2019) Advancing long-term care science through using common data elements: candidate measures 
for care outcomes of personhood, well-being, and quality of life. Gerontology \& Geriatric Medicine 5. Available at https://doi.org/10.1177/2333721419842672.

Egbu J, Wood G and Egbu C (2011) The Changing Face of Sheltered Housing for the Elderly: Past Present and the Future. Available at http://www.arcom.ac.uk/-docs/proceedings/ar2011-0573-0581_Egbu_Wood_Egbu. pdf.

Fox S, Kenny L, Day MR, O'Connell C, Finnerty J and Timmons S (2017) Exploring the housing needs of older people in standard and sheltered social housing. Gerontology \& Geriatric Medicine 3. Available at https://doi.org/10.1177/2333721417702349.

Graneheim UH, Lindgren BM and Lundman B (2017) Methodological challenges in qualitative content analysis: a discussion paper. Nurse Education Today 56, 29-34.

Gray A and Worlledge G (2018) Addressing loneliness and isolation in retirement housing. Ageing \& Society 38, 615-644.

Grol $\mathbf{R}$ and Wensing $\mathbf{M}$ (2004) What drives change? Barriers to and incentives for achieving evidencebased practice. Medical Journal of Australia 180, 57-60.

Herbers DJ and Meijering L (2015) Interpersonal relationships and subjective well-being among older adults in sheltered housing. Research on Ageing and Social Policy 3, 14-44.

Home and Rent (2019) Allt fler trygghetsboenden- men pensionen räcker inte alltid till. Available at https:// www.hemhyra.se/nyheter/allt-fler-trygghetsboenden-men-pensionen-racker-inte-alltid-till/. (In Swedish)

Howe AL, Jones AE and Tilse C (2013) What's in a name? Similarities and differences in international terms and meanings for older people's housing with services. Ageing \& Society 33, 547-578.

Iecovich E (2016) Live-in care workers in sheltered housing for older adults in Israel: the new sheltered housing law. Journal of Aging \& Social Policy 28, 277-291.

Lindahl L, Andersson M and Paulsson J (2018) Perceived safety in extra-care housing for senior residents. Journal of Housing for the Elderly 32, 58-72.

Ministry of Health and Social Affairs (2008) Bo Bra Hela Livet (SOU 2008:113). Available at http://www. regeringen.se/49b6a7/contentassets/31ff7f2c65644ca8bc677a8ed15c0d2b/bo-bra-hela-livet-del-1-av-2-sou2008113. (In Swedish)

National Board of Health and Welfare (2019a) Vård och omsorg om äldre. Lägesrapport 2019. Available at https://www.socialstyrelsen.se/globalassets/sharepoint-dokument/artikelkatalog/ovrigt/2019-3-18.pdf. (In Swedish)

National Board of Health and Welfare (2019b) Boende och stöd för äldre. Available at https://www.socialstyrelsen.se/stod-i-arbetet/aldre/boende-och-stod-aldre/. (In Swedish)

Patomella AH, Sandman PO, Bergland $\AA$ and Edvardsson D (2016) Characteristics of residents who thrive in nursing home environments: a cross-sectional study. Journal of Advanced Nursing 72, 21532161.

Percival J (2000) Gossip in sheltered housing: its cultural importance and social implications. Ageing e Society 20, 303-325.

Pinto S, Fumincelli L, Mazzo A, Caldeira S and Martins JC (2017) Comfort, wellbeing and quality of life: discussion of the differences and similarities among the concepts. Porto Biomedical Journal 2, 6-12.

Senior Life (2021) Vad kostar det? Available at https://seniorval.se/bra-att-veta/vad-kostar-det-1. (In Swedish)

Statistics Sweden (2021) Hyra i hyreslägenheter efter län och kommun. År 2016-2020. Available at https://www. statistikdatabasen.scb.se/pxweb/sv/ssd/START_BO_BO0406_BO0406E/BO0406Tab05/. (In Swedish)

The Swedish Academy Dictionary (2007) Trivsel. Available at https://svenska.se/saob/?id=T_2391-0395. R5vI\&pz=7. (In Swedish)

Umeå University (2019) U-age. Available at https://www.umu.se/en/research/groups/u-age/.

van Bilsen P, Hamers J, Groot W and Spreeuwenberg C (2008) Sheltered housing compared to independent housing in the community. Scandinavian Journal of Caring Sciences 22, 265-274.

Cite this article: Corneliusson L, Sköldunger A, Sjögren K, Edvardsson D (2023). '100 metres to the liquor store and 300 meters to the cemetery' - individual, social, environmental and organisational facilitators and barriers to thriving in Swedish sheltered housing models. Ageing \& Society 43, 1068-1088. https://doi.org/ $10.1017 / \mathrm{S} 0144686 \mathrm{X} 2100101 \mathrm{X}$ 